\title{
Functional Outcomes for Combined Acute Anterior and Posterior Cruciate Knee Injuries Treated Non-Operatively
}

\author{
Naoki Wada1 $^{*}$, Masashi Kimura ${ }^{2}$, Masayuki Tazawa' ${ }^{3}$, Yoko Ibe ${ }^{3}$, Kenji Shirakura1 \\ ${ }^{1}$ Department of Rehabilitation Medicine, Gunma University Graduate School of Medicine, Maebashi, Japan \\ ${ }^{2}$ Gunma Sports Medicine Research Center, Zenshukai Hospital, Maebashi, Japan \\ ${ }^{3}$ Division of Rehabilitation Medicine, Gunma University Hospital, Maebashi, Japan \\ Email: nwada@gunma-u.ac.jp
}

Received 8 May 2014; revised 23 June 2014; accepted 4 July 2014

Copyright (C) 2014 by authors and Scientific Research Publishing Inc.

This work is licensed under the Creative Commons Attribution International License (CC BY). http://creativecommons.org/licenses/by/4.0/

(c) $\underset{\mathrm{EY}}{\mathrm{B}}$ Open Access

\begin{abstract}
Introduction: results after non-operative management for knees sustaining combined acute anterior and posterior cruciate ligament tears were presented. Subjects: 13 patients, 10 with medial, and 3 with lateral ligament injury. Methods: non-operative management consisted of employing a brace to prevent sagittal translation of the tibia. Quadriceps muscle and early passive knee motion exercises in the brace was encouraged immediately after arthroscopy. Weight-bearing was forbidden for 3 weeks. The brace was not removed for 3 months. Follow-up periods ranged from 2 to 6 years (mean, 3 years 2 months). Results: none, but one patient had a slight restriction of knee flexion. Quadriceps muscle strength revealed an average of $89.0 \%$ of normal side. The knee score indicated 2 patients rated good, 3 rated fair, and 8 rated poor. The score correlated with measurements of anterior and posterior translation on the stress radiograph significantly. Stress radiography revealed that anterior laxity was reduced better than posterior laxity significantly. Conclusion: non-operative brace therapy can be considered for this combined injury as the initial treatment. A late reconstruction would be performed when the result was not satisfactory. Preserved range of motion and muscle strength after brace therapy had a great advantage to the late reconstructive surgery.
\end{abstract}

\section{Keywords}

Knee, Multiple Ligament Injury, Non-Operative Management, Anterior Cruciate Ligament, Posterior Cruciate Ligament

\footnotetext{
${ }^{*}$ Corresponding author.
}

How to cite this paper: Wada, N., Kimura, M., Tazawa, M., Ibe, Y. and Shirakura, K. (2014) Functional Outcomes for Combined Acute Anterior and Posterior Cruciate Knee Injuries Treated Non-Operatively. Open Journal of Orthopedics, 4, 169175. http://dx.doi.org/10.4236/ojo.2014.47028 


\section{Introduction}

Non-operative management for the medial collateral ligament (MCL) tear can lead to excellent functional outcome [1]. Clinical studies referred to the possibility of preserving the stability of knees with acutely torn anterior cruciate ligament (ACL) using non-operative treatment [2]. Non-operative methods have also been widely accepted as the most appropriate treatment for isolated tears of the posterior cruciate ligament (PCL) [3]. Ligament tears of the knee, however, may progress differently from an isolated injury when they are associated with other ligament injuries [4] [5].

There were many reports discussing the results after operative management for multiple ligament tears, only a few reports, however, had revealed follow-up after non-operative management for acute combined ACL and PCL injury [6] [7]. Chronic cruciate instabilities were reported to be successfully treated with late reconstruction [8] [9]. Aim of the study is to document results after non-operative management using a knee brace for acute combined ACL and PCL ruptures.

\section{Materials and Methods}

Non-operative treatment for combined ACL and PCL tears of the knee was performed on consecutive 13 patients. All patients underwent arthroscopy within 2 weeks after the initial injury. The diagnosis of ligament injuries was based upon arthroscopic findings, instability tests under anesthesia, magnetic resonance imaging and stress radiography. Ligament injuries which were complicated with avulsion fracture at the stump-end were excluded. The knees of high energy injuries with neurovascular injuries and/or dislocation which needed reduction procedures were not included [10]. There were no patients of bilateral knee involvement.

The subjects were 13 patients sustaining acute complete tears on both of ACL and PCL. There were 10 men and 3 women, 10 of whom associated with medial capsular ligament, and 3 with lateral capsular ligament injury. The age at the time of injury ranged from 17 to 58 years (mean \pm SD, $39.2 \pm 13.4$ years). There were 7 right and 6 left knee injuries. The injury occurred during sporting activity in 7 patients, 2 resulted from traffic accidents, and 4 involved either a fall or an accident at work.

The treatment employed an ankle-to-groin-brace designed to prevent abnormal sagittal motion of the tibia during the exercise (Figure 1). No surgery was performed on the cruciate ligament injuries. The knee braces were secured immediately after the arthroscopic examinations. Continuous passive motion (CPM) and isometric active straight leg raising (SLR) exercise was encouraged in the brace on the beginning day after arthroscopy. The passive motion exercise was started at $20^{\circ}$ flexion and active motion was then allowed through the 2nd week. This motion was increased gradually until a full range of motion was obtained.

The isotonic and isokinetic quadriceps exercise was carried out at less than $60^{\circ}$ of flexion. Weight-bearing was forbidden for 3 weeks, and full weight-bearing was permitted in the brace at 6 weeks. The brace was not removed for 3 months. The patient was then permitted to change from the brace to a knee support. Non-competitive athletic activity was permitted after 4 months, and the activity level was increased gradually to tolerable levels.

All of 13 patients returned to our clinic for a reexamination after a mean period of 3 years 5 months (range, 2

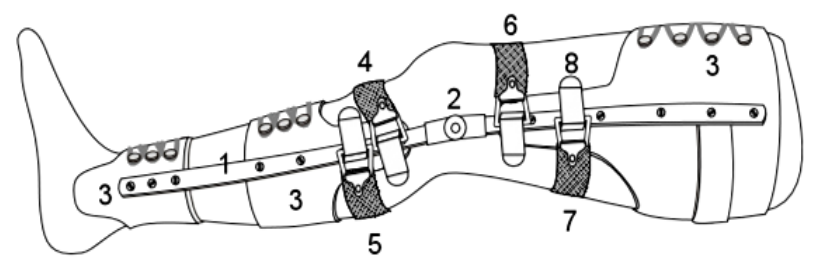

The knee brace provides frames (1) with joints (2) and leather covers (3). Anterior and posterior elasticized straps are attached to the frames and control anterior movement of the leg (4) when the knee is extended, and prevent posterior movement (5) when the knee is bent. Counter forces are provided to the thigh $(6,7)$. The buckles anchor the elasticized straps at the frames (8).

Figure 1. Knee brace for combined anterior and posterior cruciate ligament injury. 
year to 6 years 1 month). Reexamination consisted of measuring the range of motion (ROM), detecting manual instability tests, stress radiography, measuring quadriceps muscle strength, assessing knee function and a questionnaire detailing their activity levels.

The instability tests consisted of Lachman test, pivot shift sign, posterior drawer test at $90^{\circ}$ of knee flexion, posterior sag, abduction stress test and adduction stress test. Lachman test was considered to be positive when the firm endpoint was not detected. The grade of varus and valgus instability was determined using the criteria of grade 1 -full stability at both $0^{\circ}$ and $30^{\circ}$ of flexion; grade 2 -full stability at $0^{\circ}$ of flexion but unstable to at $30^{\circ}$ of flexion; and grade 3 - unstable at both $0^{\circ}$ and $30^{\circ}$ of flexion. Quadriceps muscle torque was measured using an isokinetic machine (Cybex 2, Medway, MA, USA). The test was performed at a velocity of $180^{\circ} / \mathrm{sec}$, range from $0^{\circ}$ to $90^{\circ}$. The percent value of the control side at the peak torque was adopted.

Stress X-ray views of the anterior translation of the tibia were obtained for both injured and uninjured knees on 10 patients at injury and 13 patients at follow-up. An account was given of the radiological documentation of the Lachman test with the aid of a forced translation apparatus (TelosStress Device; Fallston, MD, USA). A lateral view of radiograph was taken when a forward force of $15 \mathrm{~kg}$ was applied to the proximal portion of the tibia through the thrust pad of the apparatus. The anterior translation of the tibia was measured on the radiograph $(\mathrm{mm})$ and compared with the contralateral side. The difference between the injured and uninjured knee was greater than $5 \mathrm{~mm}$ in ACL deficient knees [11].

Stress views of posterior translation of the tibia were taken for the injured knees in 9 subjects at time of injury and 11 knees at follow-up. The posterior translation of the tibia during the posterior drawer test at $90^{\circ}$ of flexion was measured on the lateral view of radiographs with the aid of a Telos Device. Mid-point displacement ratio, modification of Jacobsen's method, was calculated using the stress radiograph. A ratio of less than $45 \%$ was thought to be a PCL injury [12].

The knee rating score was determined according the scoring scale of the Japanese Orthopedic Association for knee ligament injuries (JOA score) based on a total of 100 points [13]. The results were graded good for total scores of 90 - 100 points, fair for 75 - 89, poor at 74 and lower. The patients were interviewed about their participation in sports activity at the follow-up examination, and were classified into three levels which were competitive, recreational and no participation. The patients also provided responses to a questionnaire which dealt with their satisfaction for the results; contented or discontented.

The Chi-square test was used to analyze the difference between improvements of anterior and posterior laxity. Pearson's correlation coefficient was used for the analysis of correlation between the measurements of stress views, muscle strength and knee rating scores at follow-up. The statistical software Statcel (OMS Ltd., Japan) was used for statistical analyses. A p $<0.05$ was rated as significant.

The study was approved by the Institutional Review Board of Gunma Sports Medicine Research Center. All patients provided their signed informed consent to participate.

\section{Results}

No patients but one with MCL injury had a restriction of $10^{\circ}$ of flexion compared with contralateral normal side at follow-up.

Lachman test detected a firm endpoint in 10 of the 13 patients. Pivot shift sign was negative in 4 patients. Both of the posterior drawer test and posterior sag were negative in one patient. Medial instability of Grade 3 severity at injury was improved to Grade 1 severities in 6 of the 10 patients with MCL injury, and the remaining 4 showed no definite improvement in the abduction stress test. Adduction stress test indicated only one of the 3 patients with lateral capsular ligament injury improved from Grade 3 to Grade 2 severity, and the other 2 remained at Grade 3 severity.

Stress X-ray views documented that the side-to-side difference in anterior translation of the tibia ranged from 0 to $11.5 \mathrm{~mm}$ (mean, $5.0 \pm 3.9$ ) at follow-up. Seven (6 of 10 with medial capsular injury and one of 3 with lateral capsular injury) were reduced to a normal range of $5 \mathrm{~mm}$ and less. Mid-point ratios on the posterior stress view were from $36.0 \%$ to $61.8 \%$ (mean, $46.7 \pm 7.3$ ). Seven ( 4 of 9 with medial capsular injury and one of 3 with lateral capsular injury) demonstrated normal ratios of more than $45 \%$.

Anterior laxity was improved in 8 of 10 patients, the posterior laxity, however, was reduced in 3 of 8 when compared with those at injury. The anterior laxity improved more than the posterior laxity, and there was a significant difference between them $(p<0.05)$. 
Quadriceps muscle strength during isokinetic performance ranged from 67\% to $109 \%$ (mean, $88.5 \pm 14.2$ ) of contralateral normal side. Three of the 13 patients could not achieve $80 \%$ of the normal side.

JOA score ranged from 19 to 100 points (mean, $60.3 \pm 26.4$ ). Two patients rated good, 3 rated fair, and 8 rated poor. Two patients were participating in a competition (American football and snowboarding), 4 in a recreational sporting activity, and remaining 7 did not participate in any sporting activity.

The questionnaire with patients' satisfaction revealed 8 contented, 4 discontented and one undecided with the results of non-operative treatment. The discontented patients showed the low quadriceps muscle strength and poor sporting activities. The three patients underwent simultaneous ACL and PCL reconstruction after the follow-up examinations (Table 1 ).

The knee score correlated with the side-to-side difference of anterior translation of the tibia $(\mathrm{R}=-0.759, \mathrm{p}<$ 0.01 , Figure 2$)$ and the mid-point ratio $(\mathrm{R}=0.629, \mathrm{p}<0.05$, Figure 3$)$ at follow-up. The muscle strength did not show a significant correlation with the score. Stable knees on the stress views achieved better functional results than the unstable knees.

\section{Discussion}

A non-operative method is preferable for acute isolated tears of the knee ligament, and can be followed by a late reconstruction if the initial treatment is unsatisfactory [1]. Conventional non-operative management for knee injuries had consisted of immobilization and following rehabilitation program after the removal of the cast. Immobilization has been, however, shown to be detrimental to healing ligaments, while early motion increases tensile strength [14]. One report [2] indicated a brace therapy for isolated ACL injury and more than 50\% were healed through second look arthroscopy. These studies suggest that a knee ligament injury can be healed by non-operative methods, and an early motion had a beneficial effect in ligament healing.

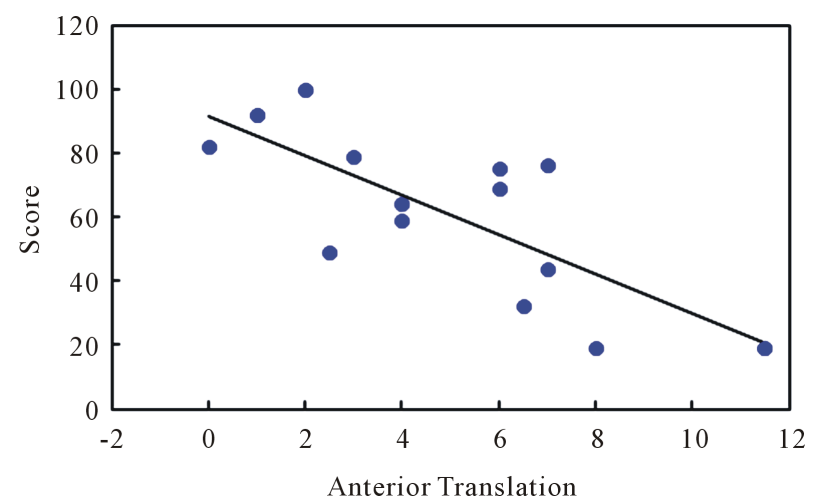

Figure 2. Correlation between anterior laxity and score $(\mathrm{n}=$ 13).

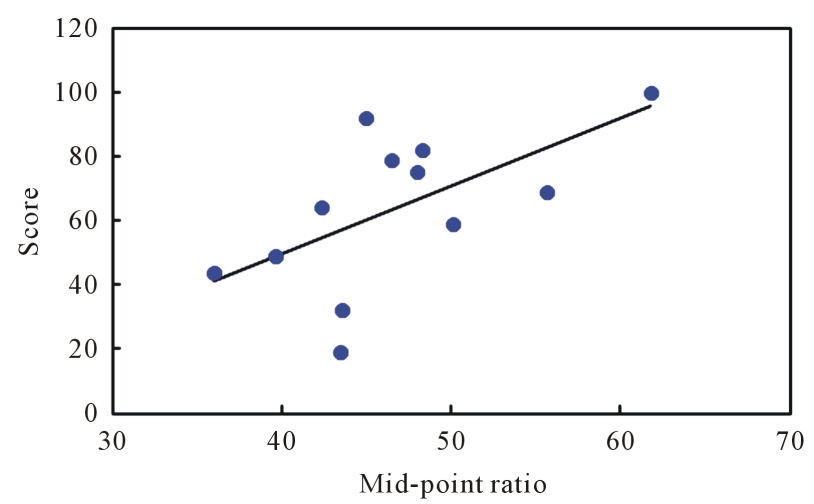

Figure 3. Correlation between posterior laxity and score $(\mathrm{n}=$ 12). 


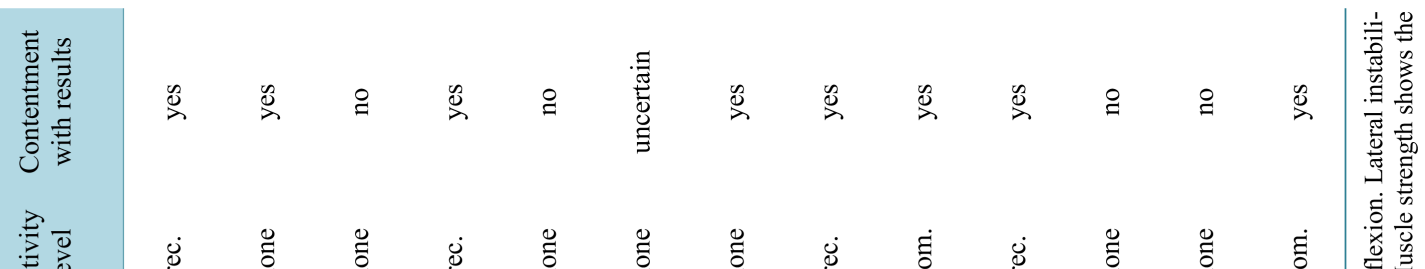

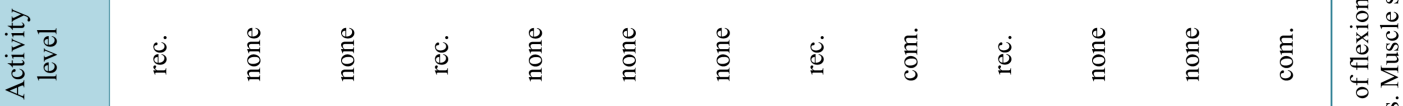

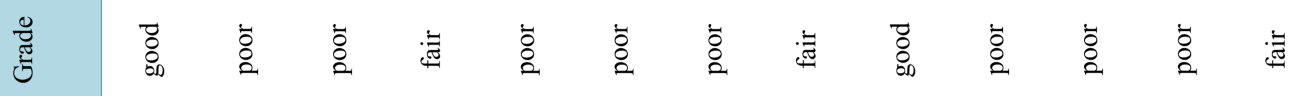

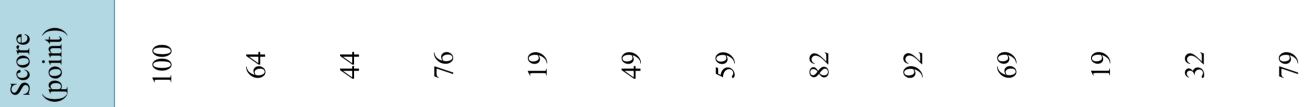

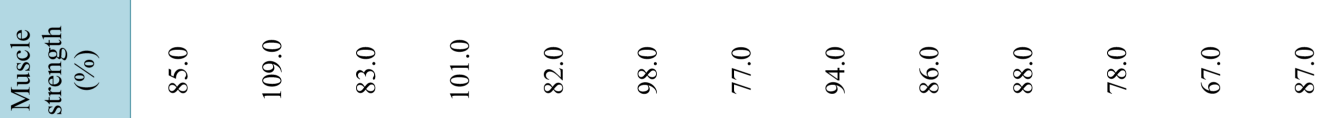

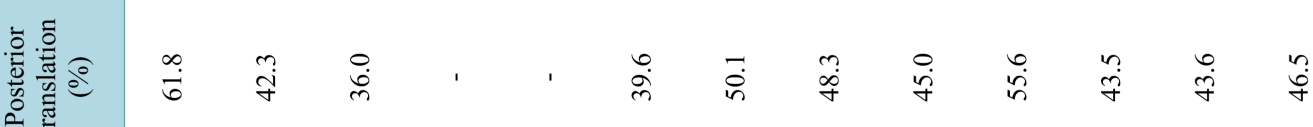

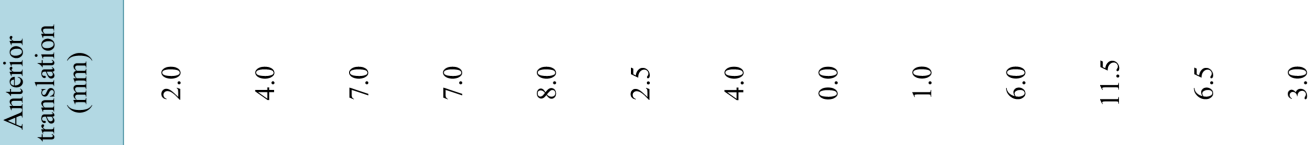

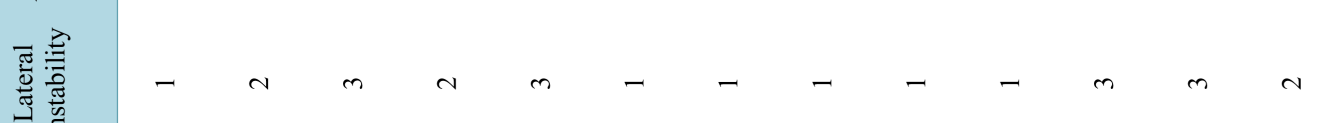
.ั0 豙离

产产

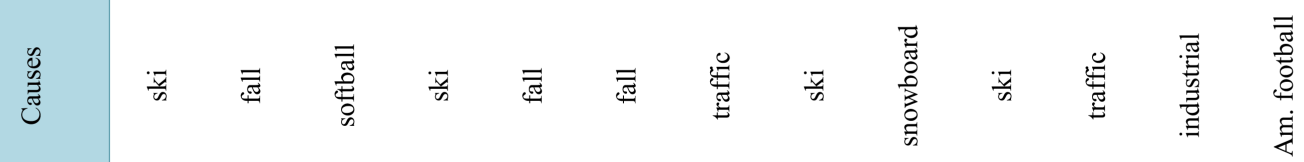

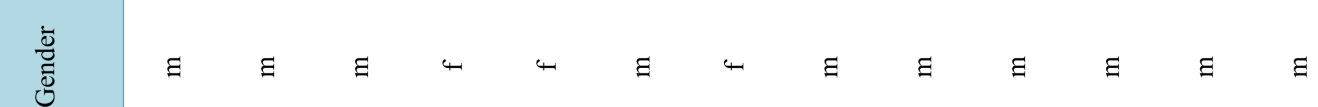

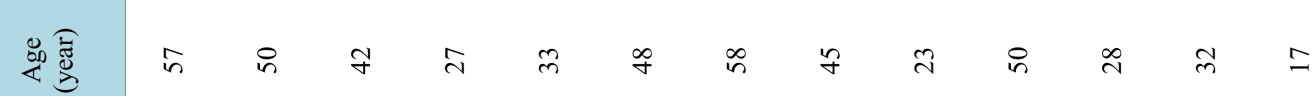


Investigators who recommend non-operative approach have also suggested that it is only applicable to isolated ligament injury claiming that early motion exercise is not indicated when this is combined with other ligament injuries [14] [15]. Bray [15] has verified the necessity for short-term joint immobilization during early intervals when the MCL and ACL were transected in rabbits. Lechner and Dahners [14] concluded that ligament sutures protected the joint from wide displacement when the secondary restraint was transected, allowing the healing ligament to maintain its effective length. In the present study, a brace was designed to prevent strain to the cruciate ligaments instead of the surgical procedure, permitting immediate passive motion exercises.

Preserved muscle strength has been identified as being an important factor in the success of treatment for knee ligament injury [16]. Contraction of the quadriceps muscle under the open kinetic chain produces an anterior translation of the tibia when the knee is extended and posterior force when the knee is flexed, a condition unfavorable for a cruciate ligament injury [17]. The brace provided sagittal restraints during range of motion as well as quadriceps exercises.

Petersen et al. [16] compared the results after primary and late ACL reconstruction in patients with combined ACL and MCL injury. Their conclusion was that patients with a late ACL reconstruction had no differences in the stability and muscle strength but a lower late of loss of extension and better functional scores than those of early reconstructions. Taylor et al. [6] recommended conservative treatment for severe multiple injury due to better stability and range of motion than those after operative procedures. Our results showed good range of motion and muscle strength which were favorable to the late reconstruction [18].

Knee score indicated that more than half of the patients of this series rated poor and did not participate in any sporting performances. The result was worse than those after isolated ACL and/or PCL injury as presented in the previous reports [2] [3]. The combined injury was more difficult when managed conservatively than the isolated ligament injury. The present study indicated that the score correlated with the stability on the stress view and the results depended on the improvement of the sagittal instability.

There was no evidence of significant difference between improvement of varus and valgus instabilities in our study due to the small number of cases with lateral capsular injury. There have been some reports which emphasized the role of posterolateral structures in posterior and varus stability [3] [19]. The present study indicates that a conservative method of treatment improved PCL insufficiency significantly less than that of ACL. Combined injury of PCL and posterolateral ligament should be managed by operative methods [3] [20]. The non-operative management may be less crucial for the combined ACL and PCL injury when it associated with lateral capsular ligament injury than medial ligament injury.

\section{Conclusion}

Non-operative management for acute combined ACL and PCL injury resulted in poor functional score, but no loss of motion and good quadriceps muscle strength. Brace therapy can be considered for this combined injury as an initial treatment, and would be followed by a late reconstruction in case of the achieved stability and function is not satisfactory. Preserved range of motion and muscle strength after brace therapy has a clear benefit in a late reconstructive surgery.

\section{Disclosure of Conflict of Interest}

The authors did not receive and will not receive benefits or funding from any commercial party related directly or indirectly to the subject of this article.

\section{References}

[1] Morelli, V., Bright, C. and Fields, A. (2013) Ligamentous Injuries of the Knee: Anterior Cruciate, Medial Collateral, Posterior Cruciate, and Posterolateral Corner Injuries. Prim Care, 40, 335-356. http://dx.doi.org/10.1016/j.pop.2013.02.004

[2] Ihara, H., Miwa, M., Takayanagi, K. and Nakayama, A. (1994) Acute Torn Meniscus Combined with Acute Cruciate Ligament Injury. Second Look Arthroscopy after 3-Month Conservative Treatment. Clinical Orthopaedics, 307, 146154.

[3] Mariani, P.P., Margheritini, F., Christel, P. and Bellelli, A. (2005) Evaluated of Posterior Cruciate Ligament Healing: A Study Using Magnetic Resonance Imaging and Stress Radiography. Arthroscopy, 21, 1354-1361. http://dx.doi.org/10.1016/j.arthro.2005.07.028 
[4] Bray, R.C., Leonard, C.A. and Salo, P.T. (2003) Correlation of Healing Capacity with Vascular Response in the Anterior Cruciate and Medial Collateral Ligaments of the Rabbit. Journal of Orthopaedic Research, 21, 1118-1123. http://dx.doi.org/10.1016/S0736-0266(03)00078-0

[5] Fanelli, G.C., Orcutt, D.R. and Edson, C.J. (2005) The Multiple-Ligament Injured Knee: Evaluation, Treatment and Results. Arthroscopy, 21, 471-486. http://dx.doi.org/10.1016/j.arthro.2005.01.001

[6] Taylor, A.R., Arden, G.P. and Rainey, H.A. (1972) Traumatic Dislocation of the Knee, a Report of Forty-Three Cases with Special Reference to Conservative Treatment. Journal of Bone and Joint Surgery, 54B, 96-102.

[7] Richter, M., Bosch, U., Wippermann, B., Hofmann, A. and Krettek, C. (2002) Comparison of Surgical Repair or Reconstruction of the Cruciate Ligaments versus Nonsurgical Treatment in Patients with Traumatic Knee Dislocations. American Journal of Sports Medicine, 30, 718-727.

[8] Fanelli, G.C. and Edson, C.J. (2002) Arthroscopically Assisted Combined Anterior and Posterior Cruciate Ligament Reconstruction in the Multiple Ligament Injured Knee: 2- to 10-Year Follow-Up. Arthroscopy, 18, 703-714. http://dx.doi.org/10.1053/jars.2002.35142

[9] Strobel, M.J., Schulz, M.S., Petersen, W.J. and Eichhorn, H.J. (2006) Combined Anterior Cruciate Ligament, Posterior Cruciate Ligament, and Posterolateral Corner Reconstruction with Autogenous Hamstring Grafts in Chronic Instabilities. Arthroscopy, 22, 182-192. http://dx.doi.org/10.1016/j.arthro.2005.11.001

[10] Schenck Jr., R.C., Hunter, R.E., Ostrum, R.F. and Perry, C.R. (1999) Knee Dislocations. In: Zukerman, J.D., Ed., Instructional Course Lectures, AAOS, Rosemont, 515-522.

[11] Garces, G.L., Perdomo, E., Guerra, A. and Cabrera, B.R. (1995) Stress Radiography in the Diagnosis of Anterior Cruciate Ligament Deficiency. International Orthopaedics, 19, 86-88. http://dx.doi.org/10.1007/BF00179966

[12] Jacobsen, K. (1976) Stress Radiographical Measurement of the Antero-Posterior, Medial and Lateral Stability of the Knee Joint. Acta Orthopaedica Scandinavica, 47, 335-344. http://dx.doi.org/10.3109/17453677608992002

[13] Ikeuchi H. (1994) Criteria for Evaluating Ligament Injuries of the knEe. In: The Japanese Orthopedic Association, Ed., Assessment Criteria for Knee Diseases and Treatments, Kanehara, Tokyo, 186.

[14] Lechner, C.T. and Dahners, L.E. (1991) Healing of the Medial Collateral Ligament in Unstable Rat Knees. American Journal of Sports Medicine, 19, 508-512. http://dx.doi.org/10.1177/036354659101900517

[15] Bray, R.C., Shrive, N.G., Frank, C.B. and Chimich, D.D. (1992) The Early Effects of Joint Immobilization on Medial Collateral Ligament Healing in an ACL-Deficient Knee. A Gross Anatomic and Biomechanical Investigation in the Adult Rabbit Model. Journal of Orthopaedic Research, 10, 157-166. http://dx.doi.org/10.1002/jor.1100100202

[16] Petersen, W. and Laprell, H. (1999) Combined Injuries of the Medial Collateral Ligament and Anterior Cruciate Ligament, Early ACL Reconstruction versus Late ACL Reconstruction. Archives of Orthopaedic and Trauma Surgery, 119, 258-262. http://dx.doi.org/10.1007/s004020050405

[17] Shirakura, K., Kato, K. and Udagawa, E. (1992) Characteristics of the Isokinetic Performance of Patients with Injured Cruciate Ligaments. The American Journal of Sports Medicine, 20, 754-760. http://dx.doi.org/10.1177/036354659202000620

[18] Millett, P.J., Wickiewicz, T.L. and Warren, R.F. (2001) Motion Loss after Ligament Injuries to the Knee. Part 1: Causes. American Journal of Sports Medicine, 29, 664-675.

[19] Skyhar, M.J., Warren, R.F., Ortiz, G.J., Shwartz, E. and Otis, J.C. (1993) The Effects of Sectioning of the Posterior Cruciate Ligament of the Posterolateral Complex on the Articular Contact Pressure within the Knee. Journal of Bone and Joint Surgery, 75A, 694-699.

[20] Jarvinen, M., Kannus. P. and Johnson, R.J. (1991) How to Treat Knee Ligament Injuries? Annales Chirurgiae et Gynaecologiae, 80, 134-140. 
Scientific Research Publishing (SCIRP) is one of the largest Open Access journal publishers. It is currently publishing more than 200 open access, online, peer-reviewed journals covering a wide range of academic disciplines. SCIRP serves the worldwide academic communities and contributes to the progress and application of science with its publication.

Other selected journals from SCIRP are listed as below. Submit your manuscript to us via either submit@scirp.org or Online Submission Portal.
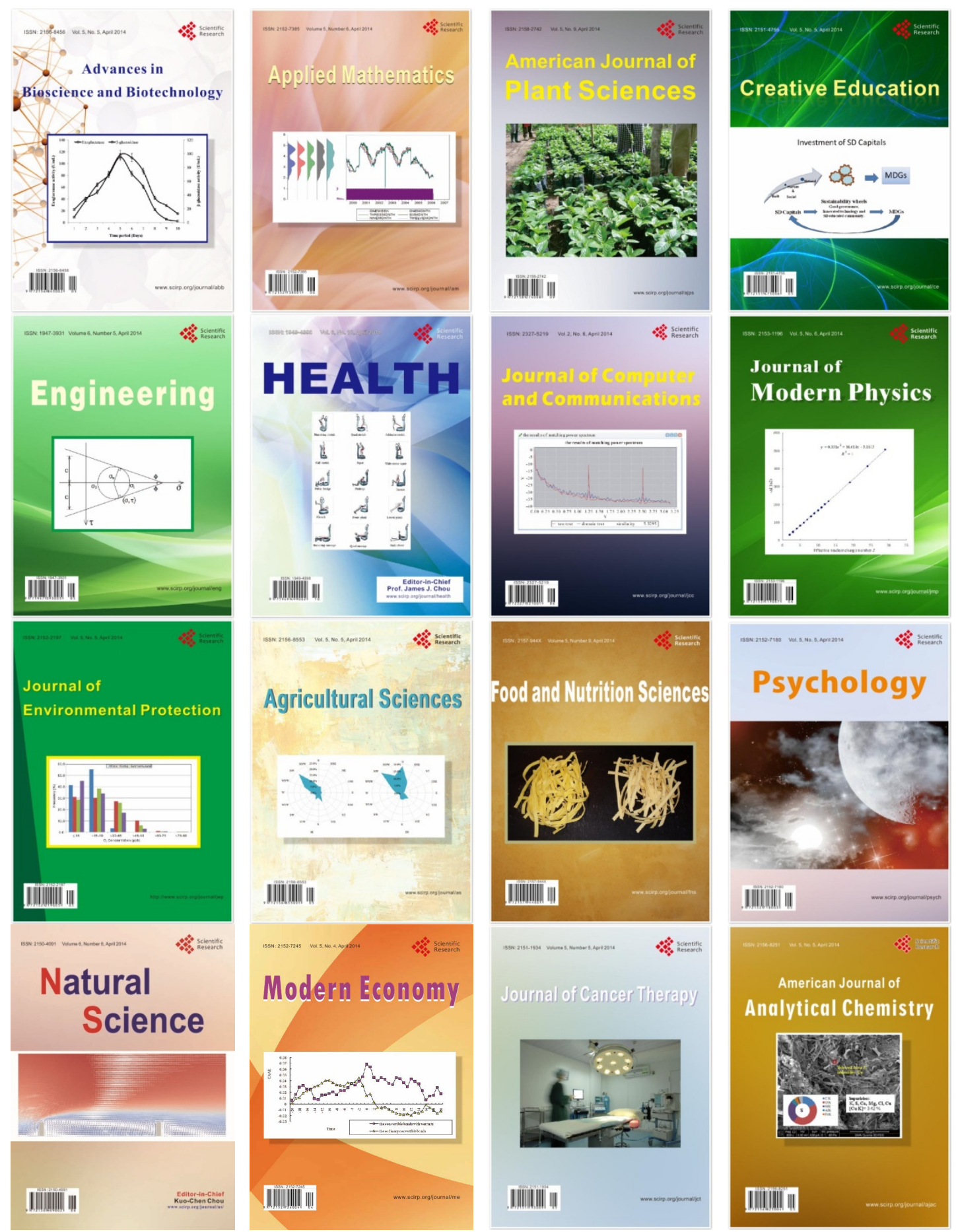